Article

\title{
Ambitions of Bushfalling through Further Education: Insights from Students in Cameroonian Universities
}

\author{
Henrietta Nyamnjoh \\ Department of Sociology, University of Cape Town, 7701 Rondebosch, South Africa; E-Mail: henrietta.nyamnjoh@uct.ac.za
}

Submitted: 2 October 2020 | Accepted: 10 December 2020 | Published: 25 March 2021

\begin{abstract}
Following a surge in civil unrest, the need and ambitions to migrate have increased among young Cameroonians. This article explores how Cameroonian youth and graduates use education as a gateway for migration, selecting new routes and destinations to maximise their chances of migration. Drawing on in-depth interviews with aspiring migrants, I show that long-standing aspirations to migrate have led to a symbiotic relationship between aspiring migrants and migration agents who facilitate and determine the route and destination for the entire process. This relationship reflects aspiring migrants who desire to migrate at all cost rather than planning carefully, often with little information guiding in the process. I argue that migration responds to cultural and political influences as much as ontological (in)security that cannot be defined solely in economic terms. The meaning of 'successful' migration is produced and reified through the overt display and interpretations of migration.
\end{abstract}

\section{Keywords}

bushfaller; Cameroonians; education; further education; migration syndicate; youth aspirations

\section{Issue}

This article is part of the issue "Decision-Making under Uncertainty: African Migrants in the Spotlight" edited by Didier Ruedin (University of the Witwatersrand, South Africa / University of Neuchâtel, Switzerland).

(C) 2021 by the author; licensee Cogitatio (Lisbon, Portugal). This article is licensed under a Creative Commons Attribution 4.0 International License (CC BY).

\section{Introduction}

Sitting at an internet café in Yaoundé, Cameroon in February 2019, as I watched those who came in to use the internet for various works, two young men caught my attention. They were using one computer. Judging from their conversation, I gathered that they were struggling to fill in online forms. I approached them to find out exactly what they were doing. Peter was helping Jake fill out an online application form to study in a Turkish University, but there was no programme for English or English Literature as envisioned, and so he discontinued with the application process. I followed them outside as they left. In an informal conversation with both, Jake told me he returned from Dubai in October 2018 and is currently exploring ways of going back or going out to pursue further education. Jake had hoped to work in Dubai, however, and articulated that:
The 'line' [broker] that worked the Dubai connection gave me wrong information, with assurances that there's a job waiting for me. But after three months, I didn't get what I went there for within the timeframe I was in Dubai. So, when my visa expired, I had to come back because I couldn't find any good job and the menial jobs I had was just to pay rent for my bed space. I came back poorer than I left, all my money gone!

All the names used for personal communications in this article are pseudonyms. Jake regretted that his money could have been spent on studying in Cyprus but was instead wasted on a broker. Despite these failed attempts, Jake's interest to migrate was sustained: "They always say don't put all your eggs in one basket, right? I am looking for scholarships, if possible, to study out."

The struggles of Jake and Peter to opt for education as a means to migrate resonate with many Cameroonian Anglophone youth and students who want to "fall bush 
at all cost" (Alpes, 2012). Migration, commonly referred to as 'bushfalling' is a farming metaphor that considers migration as going hunting or foraging and sending remittances or bringing hunting trophies to the families back home in the form of financial and material objects (Alpes, 2012; Nyamnjoh, 2011). In this article, I draw on the stories from Anglophone Cameroonian youth like Jake and Peter, among others, to understand the prospective of pursuing education as grounding towards migration as well as the entrenched need to migrate as a deeply engrained culture within the fabric of the Anglophone society (Nyamnjoh \& Page, 2002).

Research that informs this study is underpinned by fieldwork that was carried in Buea and Yaoundé, Cameroon, in January and February 2019, and July and August 2019. In the first sojourn, eleven youths were interviewed-among whom one successfully got a visa to study in Cyprus - three parents who have paid money to migration agents to send children out, and one migration agent. In the second round, twelve participants were interviewed. This included a second migrant who also successfully got a visa to study in Cyprus, two focus group interviews, two migration agents, and one parent and a migrant who I had interviewed in my first sojourn, who I found upon my return had travelled to Cyprus. This last interview was conducted over the phone.

I also had follow-up interviews and conversations with participants I spoke with during my first visit to find out how far along they were with their plans to travel. For the purpose of this article, the aim was less to seek for representation of participants than to give detailed accounts of views of a small number of articulate participants that foreground the themes discussed here. To avoid any loss in translation, I have opted to keep participants' quotes in their original forms. In other words, quotes have not been edited in order not to alter the intended meanings/emotions that participants conveyed.

Given the well-known desire to migrate among young people, my focus was on people between 18 and 35 years of age, university graduates and current students.

There are two types among aspiring migrants: 1) Those aspiring to study abroad and go to Europe, Cyprus Turkey, and the USA, and 2) those going to Dubai to 'hustle.' In the latter case, the idea is hustling to get enough money to migrate to a better country in order to further their education. Significantly, interviews reveal the social mechanisms by which the culture of migration is transmitted within the Cameroonian youth. The data analysis followed a traditional grounded theory methodology (Charmaz, 2006) in conjunction with manual thematic sorting. Grounded theory underscores how aspiration is fanned by the notion of 'bushfaller swag.' 'Bushfaller swag' speaks to the mannerisms of visiting migrants, the conspicuous material and financial wealth that they come home with and the ways they are highly regarded in the community which incites the youth with the desire to migrate. These attitudes support claims that aspirational values are not formed in isolation but are fundamentally social, shaped by our experiences and observation of others within a cultural context (Schewel \& Fransen, 2018).

The remainder of the article is organized as follows: After the conceptual focus on the interlink between aspirations and cultural values that propel desires to migrate for education, I briefly look at the socio-economic and political situation in Cameroon that engenders migration aspirations. In the last two sections, attention is brought to the empirical findings of the research. I unpack the pathways of migration towards studies and the information flow that marks this. Lastly, I look at the role of migration agents and how they propel the desires to migrate by preying on aspirants with proposals that sound credible but at times result in failure.

\section{Aspirations of Migration Underpinned by Cultural Values}

Studies on the geography of education has tended to focus on individual levels of attainment (Waters, 2006), overlooking the fact that individual migration decisions and aspirations and education are inextricably linked and increase the likelihood to migrate (Schewel \& Fransen, 2018).

From the vantage point of these linkages, migration aspirations are less easily dismissed as poor determinants of actual migration because such a view obscures the importance of migration decision, aspirations and education. Following Schewel and Fransen (2018, p. 557), aspiration is understood less as a simple cost-benefit analyses, than as the "subjective hopes and goals that guide decision-making processes, setting the horizons within which life choices are made." However, exploring aspiration alongside cultures of migration brings together attitude and societal norms that add insights on the "behavioural link" (De Haas, 2011, p. 16) and raises awareness of the complex desires to migrate. These complex desires identify the (desires) abilities, limits, and needs of the aspirant as well as the cultural traditions and social practices that frame those abilities and limitations through time. Part of these complexities are also stimulated by the expanding of migrant social networks and migration agents that give rise to a culture of migration in the sending community where migration becomes part of people's behavioural repertoires (Cohen \& Sirkeci, 2011; Timmerman, Hemmerechts, \& De Clerck, 2014).

Included in these networks is the role of families and that of the migration agent/broker who impinge on the decision to migrate. This is more so when the desire to migrate is examined in conjunction with education given education is partly perceived as an accessible and effective strategy for attaining important goals (Carling, 2014, p. 9). Similarly, it is also a way to obtain visas and for families with economic capital to turn the desires into 'ability' (Carling, 2003). Through partic- 
ipants' stories, I argue that education as an aspiration of migration is intrinsically motivated by a culture of migration that is deeply engrained in a societal value. In other words, the culture of bushfalling accentuates migration aspirations (Carling, 2014; Carling \& Collins, 2018). I advocate that including theories drawn from cultures of migration add an overlooked facet to the work of Carling and Collins (2018) and Carling and Schewel (2018) on aspirations of migrants. While this addition highlights how drivers beyond the political and economic shape aspirations, it also contributes to a better understanding of migration aspirations that considers migrants' cultural repertoire. In doing so, I explain how cultures of migration not only influence aspirations of migration but give leverage to 'migration agents,' including migration brokers and recruiters. The central role of these actors challenges common assumptions that migrants draw on personal networks-rather than professionalized actors-to support migration processes.

From this perspective, De Haas $(2011,2014)$, Carling $(2013,2014)$, and Timmerman et al. (2014) maintain that migration aspirations are dependent on information, perceptions and value systems. Significant to ask here is what would counter information about migration produce. While the focus has largely been about information that drives aspiration, mental mapping is an important consideration as it elevates the desires into plans of where migrants would like to be and work towards its realisation. Consequently, returning migrants give credence to mental mapping while also acting as a reference group that stimulates the values attached to migration and the effects of these values on educational aspirations (Kandel \& Massey, 2002, p. 984; Theo, 2003).

The advertising effects known among Cameroonian youths as 'bushfaller swag,' reifies the perception of migration as a spatial opportunity structure and a 'natural thing,' especially when broader aspirations of life cannot be fulfilled at home (Nyamnjoh \& Page, 2002). Despite the elusiveness of aspirations of migration, Carling (2014) highlights its importance in underscoring how it propels mobility and immobility. This is precisely because of mental mapping that aspirants think, dream and see themselves already travelling while at home. His analysis suggests macro/micro/meso levels, which he conceptualises more to describe the conviction that migration is desirable and the preference for migrants overstaying their visas. Quite often, this is because of the "intrinsic and instrumental values" (Van Mol, 2016, p. 8) to be derived from migration. Van Mol, Snel, Hemmerechts, and Timmerman (2018, p. 2) allude to this as "normative influence" of migration aspirations. They refer particularly to the influence that previous migrants have on migration aspirations of prospective migrants, which ultimately creates a culture of migration.

Inasmuch as this culture resonates with Cameroonian youths, in Cameroon, it goes beyond influences of previous migrants to include a culture where migration agents become kingpins in deciding destina- tions for aspirants at a fee. Perhaps it is in this context that Eggert, Krieger, and Meier (2010) highlight the interdependence of migration and education decisions which are based on the need of skill formation in a context of exogenous migration and an imperfect labour market. Education, they note, could be halted in favour of skills acquisition as in the case of Cameroonians for who education is less an immediate concern of attending school than having the opportunity to travel.

Although the possibility of migration to developed countries encourages human capital acquisition, the ultimate is the fulfilment of the rite of passage as a 'bushfaller.' As social actors, aspiring migrants' decisions about their futures, according to Cohen and Sirkeci (2011, p. 14) are "framed by traditional beliefs, cultural expectations, and social practices/expectations that are embedded in their immediate and broader environment, which is characterized by a variety of conflicts and competitions affecting the likelihoods of decisions to migrate."

\section{Contextualising Bushfalling Aspirations in Cameroon: Conflicts, Insecurity, and Unemployment}

Anglophones are complaining, students haven't gone to school and then we have people who have shut down businesses and ghost towns, and the economy is terrible. I have friends who are doing business, just like me, they had to close their shops and run and come here. There's insecurity, someone is killed and there's fighting everywhere. You cannot do business in such an environment. So, the Anglophones are suffering. Many people are fed up with Cameroon and they see this place as a hopeless place with massive corruption and unemployment, they don't have hope in the place anymore and they believe that when they go out there, they have greener pastures.

The above excerpt, from an interview with Peter, 11 February 2019, sums up the feeling of many Cameroonian youths who are despondent by the political elites' cronyism at the expense of young unemployed graduates. Cameroon is a multilingual country with over 268 ethnic languages and two official languages of English and French that reflect the dual colonial legacy. Approximately $80 \%$ of the population speaks in French as a first language, while about $20 \%$ speaks in English. However, the political agenda in Cameroon has become increasingly dominated by the 'Anglophone problem' as a result of political, cultural, economic and social grievances expressed by the English-speaking minority (Awasom, 2020; Konings \& Nyamnjoh, 1997, pp. 207-210). Summarizing the problem, Awasom (2020, p. 265) avows that:

Is it about the marginalization (political, economic, social, cultural, and a linguistic minority) problem? Is it the forceful assimilation of Anglophone Cameroon in line with the French colonial policy in Africa? Is it 
about bad governance owing to lack of democracy and free and fair elections? Is it simply the incompatibility between Anglophone and Francophone co-existence and ways of doing things?...Its apotheosis is the birth of the Anglophone putative state of Ambazonia and the military onslaught on the Anglophone people and nation by an aggressive, callous, extractive Francophone hegemonic colonial order.

Such marginalisation can be traced back to when the Anglophone regions were under the "administration of the Southern Cameroons as an appendage of Nigeria and led to the neglect of the region's development, consequently forcing the population of Southern Cameroons to vote for unification with French Cameroons on 1 October 1961 (Konings, 2011, pp. 17-18). The current marginalisation was hardly anticipated and has continued unabated. Moreover, despite the substantive oil reserves that were discovered in the Anglophone region, they did not benefit from the natural resource or from the political leadership appointments and employment in the refinery (Agwanda, Nyadera, \& Asal, 2020; Awasom, 2020).

In October 2016, Anglophones, led by teacher's trade union and magistrates, clamoured for more autonomy against attempts by the central government to marginalize their language and culture. Among many other claims, the protesting lawyers "denounced the government's surreptitious deployment of jurists who were only conversant with French civil laws and not the common law that applied to the Anglophone regions" (Agwanda et al., 2020, pp. 5-6). Similarly, teachers complained of "Francophone teachers that were being posted to the Anglophone zone to teach in broken English thereby watering down the quality of education in the Anglophone zones" (Awasom, 2020, p. 283), all of which erode their language and culture (Anyangwe, 2014; Konings, 2011, p. 77). Such identity marginalisation dovetails Reader's (2009, p. 31) insight that identity can lead to conflict when there is the pursuit of competing needs and values within different groups or identities.

The protest reignited the Ambazonia movement that is pushing for secession or decentralisation (federalism) (Konings, 2011), and today the English-speaking regions have proclaimed themselves as Ambazonia (a name given to the English-speaking regions of Cameroon), pushing for statehood, resulting in violent clashes between government forces and militias across the two Englishspeaking regions of the country. Following calls for ghost towns, entire towns, cities, and villages in the Anglophone regions came to a standstill as schools were closed, banks and shops remained unopened, and even taxis were not operating. Between January to April 2017, internet access was cut in the two concerned regions (I myself witnessed internet blackout while out on fieldwork).

Subsequent years have witnessed vicious cycle of reciprocal killings, scores of villages being burnt to the ground, abductions, extrajudicial killings and countless numbers of both internally and externally displaced Cameroonians (Amin, 2018). The corollary has been devastating for the youths and school children following the interruption of schooling, high numbers of dropouts as they run out of conflict-ridden areas and massive unemployment for university graduates. Small and medium economies, often run by unemployed graduates, are negatively affected due to long periods of ghost towns, excessive fighting and destruction of properties. Most fled from the English-speaking provinces for safety in the French speaking areas.

Furthermore, the conflict arises within an already limping economy that has hardly recovered from the International Monetary Fund and World Bank's structural adjustment programmes in the late 1980s to early 1990s. The reforms led to an economic downturn and retrenchment from jobs in the country (Nyamnjoh, 2011, pp. 703-704, 2020). The Anglophone crisis and the economic crisis provided a recipe for precarity/uncertainty, insecurity, corruption, and furthered unemployment, particularly among the young (Jua, 2003). The effect is a heightened aspiration to migrate (Alpes, 2012; Nyamnjoh, 2014), as seen from Peter's words at the opening of this section. Against this backdrop, the Anglophone crisis serves particular narrative constructions of marginalisation among the youth who "imagine Cameroon as a prison rather than as a nation state" (Konings, 2009, p. 74). As a result, many graduates are obliged to defer their entry into adulthood because of their inability to attain economic independence. However, for many, entrance into adulthood is believed to find expression in bushfalling as an alternative pathway (Fokwang, 2008; Jua, 2003).

\section{Pathways to Migration for Studies: Schooling and Scholarships}

I think that those who have aspired to go out and maybe have had disappointments have decided to use educational means to go out. Yes, so if they go out, maybe, since they have already applied for a university there, they may just go and study maybe nine months, six months and they just drop because their main interest was not to go and study but they use the educational means for them to easily have their visa and they travel. So, when they reach there, they can just study for some few months or few years and then stop so they can continue with their main ambition, what really took them there.

In this section, I draw on Tim's interview, date 25 July 2019 , and those of other aspiring migrants and stories of migrants who have travelled from families left behind to show how, increasingly, education is seen as the easier option to migrate given the stringent visa regulations within the European Union countries and North America. Tim's excerpt expresses the sentiments shared 
by almost all the participants of this study. In Anglophone Cameroon, young people and their parents connect migration with the process of 'becoming somebody in life' as a way of mitigating blocked socio-economic mobility impinged on them by postcolonial elites' continuous cling to power and resources (Fokwang, 2008). Although schooling and formal education is seen as a major route to socio-economic mobility and expansion of opportunities for individuals in society (Crivello, 2011), for most Anglophone youths, however, this has not been the case because education does not lead to socioeconomic mobility given the high unemployment and the political/economic crisis that Cameroon is facing. Consequently, taking advantage of going out to study, even when it would not be followed through, is highly sought after (Atekmangoh, 2017; for studies in Ethiopia see also Schewel \& Fransen, 2018).

Jonah elaborates:

They are using studies like a passport to go and be doing their own things there. The main aim for them to go there is because here in Cameroon you cannot have a direct employment. If there was direct employment from countries over there, like Cyprus, Germany, people will not go directly for school, they will just go instead directly for job employment. So, when you go through school, they pay your fees, you can go like the first day, second day, then if you like, you start working your own with your company. After some time, if you have the money you go back to school.

Whereas the zeal for many aspiring migrants is to pursue education when they succeed in travelling, the socio-cultural pressures back home to send remittances outweigh studies. Similarly, the desires to embody 'bushfaller swag' dictates that they suspend studies in preference for work, as Ryan notes:

Our mindset is that we are all going to school to have money at the end. The truth is that, for me, since I am in the master's program, I can say that, when I travel, I might not really have the intention to continue studies.

Beyond socio-cultural pressures, the need to become a 'man' reduces the appetite for studies in favour of coming of age. Being a man is rooted in cultural norms of 'rite of passage' that expect men within a certain age bracket to be economically independent-marry, have children and own a house as well as look after the family back home (see also Argenti, 2007, p. 7). For migrants, this requires living a frugal life to meet these demands to prove their capacity as a man (Nyamnjoh, 2014). Becoming a man therefore is imperative to avoid perpetual infantilization of young men who are derogatorily referred to as children in order to deny them power and agency. Peter explains:
What is preoccupying my brain is to be a man. I want to have security in life that I know that if I have my children, I can take good care of them. Even if I'm married, I can take good care of my family. So being a man, is to have some financial security. You're sure that you can always be taking care of yourself and maybe some other person. So, I don't see myself like I'm already financially secure enough.

Hence, bushfalling becomes the pathway to successfully accumulate wealth and power to move out of this arrested childhood as well as negotiating transition to full social and cultural adulthood (Fokwang, 2008).

Besides the search for scholarships, Peter also looks for conferences that he can apply to for as a way of migrating. He has not been successful. He explains: "Sometimes I see conferences abroad.... a apply. Like 'One Young World,' I applied but I wasn't taken. I have applied for several conferences that I see, and youth camps and I wasn't selected."

Peter's intentions of applying for conferences were clear-to go and not return: "If I go, and it's possible, I will not come back. But I never got selected."

Whereas the desire to travel is the norm, there are those who are determined to go and pursue studies and follow the legal route, as Eric explains:

I know [that] after my studies I'm going to pursue the dream of actually going but in a legal way. And, so, maybe through...scholarship. Because I'm working very hard. I have a target this semester, 3.6 GPA upwards. Although I too have the desire to fall bush, I'm not obsessed about leaving through any magu-magu [illegal] way, I'll pursue my education.

Peter's willingness to use any means available contrasts that of Eric to go through a legal way and to pursue education. Eric's notion of travelling legally challenges the perceived notion in Cameroon among some youths that book na scam, loosely translated as 'education is a waste of time,' given that it does not lead to potential employment. According to my participants who subscribe to this notion, they opine that it is of less importance to accumulate certificates and end up unemployed, than seek ways of going out. Blaise explains:

Even if you graduate, you're either underemployed or you're unemployed, you're no different from someone who has not gone to school or doing buyam-sellam [informal trader]. Hence, most try to figure out how to leave the country, they want to make money at all costs.

Making money at all cost ties in with the notion of being a ' $m a n$ ' because that is only when they move out of trapped adulthood.

Such desires are partly induced by the crisis in Cameroon, and steeped in the social normative values 
of bushfalling, that is premised on the gains of migration ('bushfaller swag') and the display of 'development projects' at home, lavish spending and ostentatious consumerism (see also Atekmangoh, 2017).

Despite these desires to migrate, migration aspirations could lead to 'sour grapes' mechanisms (Van Mol et al., 2018), when all attempts to migrate yield no success-when aspirants apply for different scholarships with the hope of being selected, but nothing materialises. This is the case with Peter, whose unfruitful search for scholarships ended in his failed journey to Dubai:

I started looking for scholarships, Mastercard, Commonwealth and DAAD scholarships and scholarships in different universities....Because the school fee is very expensive and I couldn't afford...I applied for several scholarships, [but] I was turned down.

During my second trip to Cameroon, I caught up with Peter again at the cybercafé we had first met, and he indicated that he has been sitting there for over five hours looking for and applying for scholarships. Going to the cybercafé is part of his weekly activities where he spends long hours to ferret for scholarship opportunities:

I am always making research for scholarships. I have just been here and applying for scholarships. Unfortunately, I haven't had one. We [applied] and they selected 16 of us from Cameroon to write the final exam and do an interview with a professor in 2014, who came from Costa Rica for this purpose and, uh, he just needed one student from Cameroon.

Peter's determination to go out through education dovetails suggestions that formal education is a potential driver of both aspiration and capability to migrate (De Haas, 2014), despite the intimation by some that it is a scam. Most youths do not rely wholly on scholarship opportunities. Although women search for scholarships, most prefer to go under the guise of attending a conference or youth camp as their male counterpart. But for the most part, they depend on family networks to initiate the process for them.

\subsection{Family Networks and Chain Migration}

Studies have revealed the extensive help that migrant family members provide to enable the migration of those left behind (Nyamnjoh, 2014). This is either by facilitating family reunions or assisting travel to other destinations. Referred to as chain migration, this is seen as strategic ways of lifting families out of poverty and alleviating the financial burden of remittances on individual migrants (Atekmangoh, 2017). From this perspective, Sally explains how her uncle in the UK assisted her sister to travel to Cyprus using education as a pretext:
My elder sister is in Cyprus. Yes, my uncle in the UK processed her documents, he got the contact of one girl who is presently in Cyprus. They processed her documents [and] she is going to study in a university in Cyprus, legally. The intention was to use school as a cover up even though the school said they will pay some of the tuition, but she said no, she cannot continue studying in the country. So, the intention is when she gets a base in Cyprus, she can easily access the European Union. So, she found a way to seek an asylum in the south and she is in the process of getting her papers there in southern Cyprus. Then, from there, seeks for citizenship and she can find her means into any European country (Sally, focus group interviews, July 17, 2019).

Sally's sister has done a mental mapping of her trajectory and where she sees herself in future. Like most migrants, the first destination is often a transit or liminal zone that is characterised by years of waithood.

In the absence of family networks for many who would like to travel legally, they resort to migration agents/brokers for help.

\subsection{Taking Advantage of Their Aspirations: How Migration Agents Fuel Migration}

I met Godlove at an internet café, which doubles as his office following the long hours he spends there. He is a migration agent and a dokiman-helps fill out visa application forms for those who want to travel (il)legally at a fee or procure falsified visa documents. Having served jail time for falsifying documents for one embassy in Cameroon, Godlove has not given up his trade. In a conversation with him, he indicated the different countries and fees, including flights, that he can help travelling to:

I can get a study visa for undergraduate and postgraduate to Cyprus, Turkey, Georgia and Serbia for CFA 2.7 million FRS. For these countries, I have a partner who facilitates arrival and reception at the airport with temporary accommodation. Then there is also the Sweden asylum line for CFA 1.8million FRS. This line needs someone who is bold. The idea is to travel to Sweden on a false visa, and when one gets to the airport you create a 'motif' [deliberately lose the passport] and the police will take you to an asylum camp.

On the one hand, the increase in visa restrictiveness towards African citizens has change the character of migration to one of spatial diversification of migration (De Haas, 2014), on the other, it has deepened the gulf between dreams and legal realities creating a market in organized illegal passage (Collier, 2013). It has also emboldened brokers and aspirants to create and travel on fake documents respectively. While some brokers are known for being dishonest, Godlove's explanation of travelling on a false visa is still appealing to some whose 
friends have been fortunate to follow that route successfully. For aspirants and agents, this modus operan$\mathrm{di}$ is a contestation of stringent measures by embassies and circumventing legal routes, given their mastery of which countries are easier to get study visas for aspiring migrants. This also means that we should recalibrate the one-dimensional perception of brokers as criminals to seeing the cultural role they play in facilitating the bushfaller culture for those who dare to travel. This, however, does not discount the fact that the agents are seen, in Jane's words, as:

Individuals who are very ambitious, and they want to make money at all costs, so they tend to take advantage of peoples' desire to fall bush.

Jane's quote succinctly reveals the perception of migration agents by most, yet they are seen as an integral part of the migration process that cannot be by-passed. Migration agents are aware of the heighted desire to migrate and have taken to advertising their offers on Facebook, posters on streetlamp poles and walls of internet cafes frequented by the youth as seen in Figure 1. Similarly, others advertise their expertise in visa application processes.

These brokers seek to satisfy aspirants by 'convincingly' proposing various routes and university admission schemes with promises of facilitating the process at a fee. While such allures have been either met with marginal success, disappointment, loss of huge sums of money and frustrations, others have been able to travel through this route for education. Nevertheless, stories of frustrations abound given that syndicates prey on the gullibility of aspiring migrants by feeding them unverified informa- tion. Peter narrates his ordeal with an agent; he graduated from the university of Yaoundé 1 with an MA in English Language and Literature and has worked on various businesses to generate income to travel. In this journey, his parents had to borrow money from a micro-finance to complete what funding he had:

I met someone, he's a travel agent here [Yaoundé], he assists people to get student visas, work and tourism visas to different countries, especially Dubai. So, I have a friend whom he helped to travel abroad. So, I went to the guy and unfortunately for me I went there when he was having financial problems. So, he decided to play a trick on me.... He told me that he can help me to get a work visa but that I have to pay him CFA 1.5 million [approximately EUR 2,287]. That the company will pay the visa for me and pay a flight ticket for me to go and start working. I gave him an advance of CFA 1.000,000 FRS. And after some time, he told me that it would take about a month to do all of that. But he was turning me, and it took about three months. Later, he showed me a flight ticket that the company had paid for and the visa. And where I was living, I'd moved out of the house and sold my things. So, on the travel day he called me and asked me whether I was ready, I said yes. So later on, he called me again, I thought he was calling me that we should be going, but he told me that his brother who is in Dubai has just called him and told him that there is a problem in [the] company. That he is sorry, that he did not know, that the brother just called him now, that I should hold on a little bit, that he thinks that within the next few weeks the problem will be regulated and I could travel again.... He offered to return some of the money and
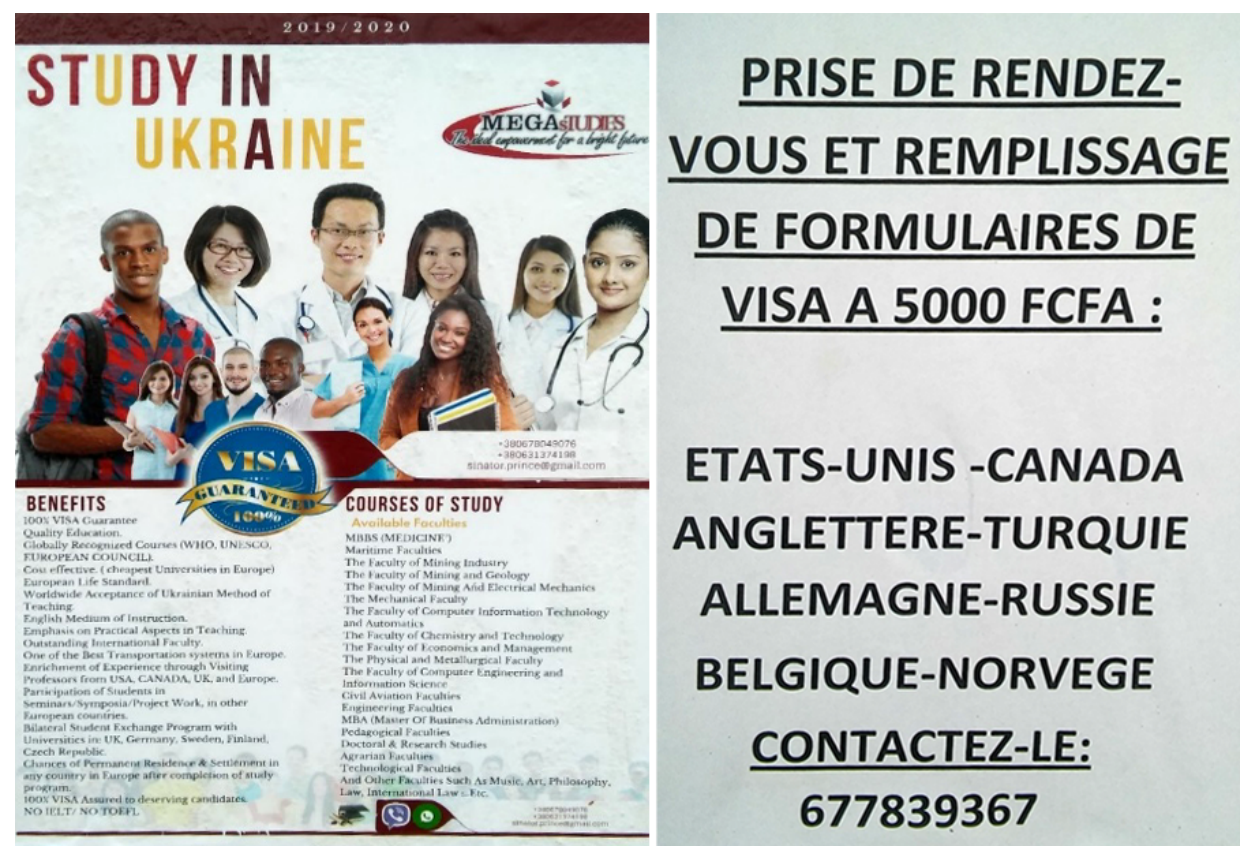

Figure 1. From left to right: Pole advertisement by broker of courses to study in Ukraine and advertisement at a cybercafé for those in need of a dokiman's assistance to fill out visa forms. Photos by the author. 
that's when I became suspicious...he stopped taking my calls and I found out where he lives and went and threatened him with death if he doesn't refund all the money. He finally refunded the money and I had to start life again.

The desperate desire of aspirants to fall bush, often without questioning the process or knowing where they are going often ends in frustration and agony, as in Peter's case. The general perception among the research participants is that the migration agents are economical with information, making it difficult for aspirants to make informed decisions. But importantly, they are noted to dabble in what Fokwang (2008, p. 243) terms as "an economy of faux dossiers" (forged documents). Consequently, like Peter, most aspirants fall into the agents' traps with very little recourse.

\subsection{Misinformation and Misrepresentation of Destination Countries by Migration Agents}

There is ample evidence that migration is self-sustaining owing to information received from existing migrants and networks (Nyamnjoh, 2014; Ramos, 2019). Such information is key as it prepares aspiring migrants towards eventual migration. However, the same cannot be said of most migration agents who care less about the welfare of their clients than about the fee to be made from assisting aspirants to travel (Alpes, 2017; Ullah, 2013). Often, the broker fee is raised by the families who either sell family-owned land or take loans, such as Ben's mother who borrowed CFA 2 million FRS (approximately EUR 3,048) and paid a broker to facilitate Ben's travel to Canada but failed. She lost the money. Similarly, Tim's sister was misinformed about a job opportunity in Kuwait and the family had to raise CFA 600, 000 FRS (approximately EUR 950) to pay the agent for her to travel. Tim explains:

Last year, my sister followed one of the Kuwait lines [agent] and travelled for a job as a domestic servant. Prior to travelling, they gave her the job description and promised her a huge sum of money as salary. But when she got there, she realised that she was to [take] care of animals. So, she spent about one month [there] and...came back home.

The desire to travel at all cost (Alpes, 2012) appears to have intensified blind trust in migration agents and heightened gullibility in aspirants. It also points to the amount of risk that both aspirants and families are willing to take to turn aspirations into reality. Jonah concurs with the above by stressing how the gullibility of aspiring migrants play a role in the way they are preyed upon by brokers:

Some just go out because of ignorance, they don't know. They just go, [some] of which...are not being educated that, if you are going to this country, this is what you meet, these are the challenges you have to face, you need to know this, you need to know that. Some of them [agents] they just say "ah massa [Mr.], it's easy to go out there." I have a friend who went to Dubai in the last two weeks, he is already back in Cameroon. He sold most of his property. He had two taxis on the road, he sold it [so] that he [could go] to Dubai. Because of the misinformation they gave him...

During this research, there was active campaign by NGOs dissuading youths from travelling to the Middle Eastern countries, especially Kuwait following numerous complaints from returnees. As most heeded the call, it signalled a downturn of business for brokers who had to devise other means of recruiting prospective migrants. They by-passed aspirants and spoke enticingly with family members abroad that are eager to send relations to Dubai.

\subsection{By-Passing Aspiring Migrants to Sell 'Lines' to Family Members Overseas}

The return rate of those who travel to Kuwait and Dubai following misinformation has become a signpost and deterrent for aspirants to look elsewhere, putting most migration agents working on these lines out of business. Consequently, they overlooked aspirants and contact family members of aspiring migrants abroad who might be willing to sponsor a relation about prospective opportunities in Dubai/Kuwait. Jonah narrates how the agent contacted his sister in America:

My older sister in US has a friend in Dubai, who is collaborating with them [agents] and told her that, Dubai dey fine [is great]. They gave her all the impression that Dubai is superb.... She called me to send her my passport, and she was telling me that she wants me to go to Dubai. I told her "I will not even step my foot there, don't even waste your time." Meanwhile, I had pleaded with my sister to pay my fee to study in Cyprus, but she refused. She doesn't have money to pay for me to study in Cyprus, now she's willing to pay a scammer 3 million [approximately EUR 4,573] for me to go to Dubai!

Jonah explained how this is done by someone with inside information about families abroad willing to sponsor someone at home. This comes at the backdrop of his parents' asking the sister to help him travel out. Alternatively, the brokers advertise on Facebook:

They put it on their Facebook status-Dubai line 2 million, working permit 3 years, good salary, CFA 700,000 FRS a month, people are eager to go.

Inasmuch as brokers by-pass aspirants to make claim over them through other family members, the latter 
equally overlook those they want to assist by affording them no say in the process. This demonstrates the interplay of structural forces that position young people into categories of dependency (Fokwang, 2008), thereby infantilizing them and excluding them of any decisionmaking processes. Migration brokers have often been looked at with disdain for preying on the vulnerabilities of aspiring migrants. Nevertheless, Jonah's experience with his sister exemplifies the complex and ambiguous relationship between aspirants and brokers. It (1) highlights the gullibility and risk taking of potential migrants and families in their desperation to migrate, (2) underscores the entrenched cultural values of migration that is reified by those abroad, and (3) shows how migration syndicates take advantage of people's naïveté. Jonah's excerpt shows the alluring imageries of a better life that is used to induce potential migrants and families to decide on moving overseas or sponsor the journey respectively (see also Ullah, 2013).

Despite the unscrupulous activities of some migration agents, there are those who explore new destinations, provide genuine 'lines' as well as networks in the destination country to enable migrants' soft landing.

\section{5. "I Don' See Cyprus Line. I Have Found an Agent That Can Secure a Passage to Cyprus": The Search for New Lines and New Agents}

A migration destination that is brokered by an agent is known as 'line,' though it is often not linear and entails lots of risk taking and anything could go wrong. Having lost about EUR 3,048 to unscrupulous agents for a failed Canada line, Ben's mother was not ready to entertain further conversations about migration agents until Ben told her that he has found a genuine 'line' to Cyprus. The losses incurred by families without repercussion underscore the moral economy that shrouds values and norms of brokering (Fassin, 2005), and highlights the hopes and fears of dealing with agents. Ben's mother was encouraged by the fact that the agent will be paid in instalments and the money will be completed after Ben arrives Cyprus. Despite her willingness to support her son to go out, she is however unwilling to pay the entire sum demanded by brokers following her recent losses, hence she welcomes the idea of paying this broker in instalments. What this shows is a sense of mutual responsibilities within families and therefore intergenerational continuity to ensuring the son becomes a 'man.'

According to Ben, the agent helped him look for university admission and accompanied him to the Turkish embassy to get a visa. When a slight complication arose, he was able to get more documents from the school to complete the consular-required documents and Ben got the visa and travelled.

The agent indicated that he is working with another friend who studied in Cyprus and who now works at the university. He said: "My aim is not to defraud anybody, we want to help young people who are desperate to trav- el, and for every successful journey, we get about five more because those who travel become our advertisers."

\section{Conclusion}

I have shown how migration aspirations and education among Cameroonian youths are intertwined and driven by cultures of migration. Extreme visa restriction, and heightened aspirations to migrate have altered the character of migration among young Cameroonians. Consequently, potential migrants use education as a front to apply for visa to migrate or intensify the search for scholarship. Nevertheless, socio-cultural prescripts have entangled and "bundled these aspirations in a way that makes it difficult to separate what is individual from what is collective, what is aspiration from what is expectation, what is for education from what is for work" (Crivello, 2011, p. 396). This is because the mindset is fixated on becoming a bushfaller in order to be a 'man' and hence a means for them to transition from children to adults.

Significantly, the desires are fed by existing sociocultural values that elevate migration as a 'natural thing' to do in order to improve the living standards of the family as well as their status among peers. Conversely, a substantial educational attainment legitimises their case of having a visa on grounds of pursuing further studies, and perhaps providing the basis for supporting this "capacity to aspire" (Appadurai, 2004). Bushfalling which is legitimised through education that is not often acted on upon arrival, for the youth is the pathway to becoming somebody, for themselves as well as for their families.

Potential migrants' desperate desires to fall bush make them easy target for the agents who prey on their vulnerability and aspiration and often operate without a legal base and take advantage of the contemporary migration flow (Ullah, 2013). Often, in practical terms, brokers fit Fokwang's (2008) description as people who operate in forged documents. However, Godlove as well as Ben's agent are representative of agents as two sides of the same coin, not sure which way the coin will go when it is tossed. This is indicative of not painting brokers with the same broad-brush stroke as dubious as we miss the point but see each on its merit. The role of migration agents therefore places them within a complex and ambiguous position that challenges the primary components of the network theory that networks are helpful in migration, contest stringent border policing, and are looked up to by aspiring migrants as the person to unlock their destiny.

Parents play a key role in unlocking this destiny as they are the main funders of the journey when aspirations result in migration. Like Peter and Ben's parents, they are expected to come up with the requested amount to turn aspirations into reality. Despite the desires to migrate, there is inevitably a discrepancy between those whose aspirations to migrate became actualised. Of all the participants who were interviewed, 
only three have finally migrated; one to Belgium and two to Cyprus.

\section{Acknowledgments}

I am grateful to the two anonymous reviewers for their insightful comments. I am thankful to Liza Cirolia, Chioma Onukogu and Sue Nyamnjoh for additional comments. Special thanks to the youth who shared their time and knowledge throughout the research period. This article is based on research that was funded in the context of the Swiss Sub-Saharan African Migration Network (S-SAM).

\section{Conflict of Interests}

The author declares no conflict of interests.

\section{References}

Agwanda, B., Nyadera, I., \& Asal, U. (2020). Cameroon and the Anglophone crisis. In O. Richmond \& G. Visoka (Eds.), The Palgrave encyclopaedia of peace and conflict studies (pp. 1-12). Cham: Palgrave Macmillan.

Alpes, J. (2012). Bushfalling at all cost: The economy of migratory knowledge in Anglophone Cameroon. African Diaspora, 5(1), 90-115.

Alpes, J. (2017). Why aspiring migrants trust migration brokers: The moral economy of departure in Anglophone Cameroon. Africa: The Journal of the International African Institute, 87(2), 304-321.

Amin, J. (2018, June 29). President Paul Biya and Cameroon's Anglophone crisis. Pambazuka News. Retrieved from https://ecommons.udayton.edu/ hst_fac_pub/142

Anyangwe, C. (2014). A country decolonised becomes coloniser: Republique du Cameroun's colonial occupation of the Southern Cameroons (Ambazonia). In F. Achankeng (Ed.), British Southern Cameroons: Nationalism \& conflict in postcolonial Africa (pp. 1-11). Victoria: Friesen Press.

Appadurai, A. (2004). The capacity to aspire: Culture and the terms of recognition. In V. Rao \& M. Walton (Eds.), Culture and public action (pp. 59-84). Palo Alto, CA: Stanford University Press.

Argenti, N. (2007). The intestines of the state: Youth, violence, and belated histories in the Cameroon grassfields. Chicago, IL: Chicago University Press.

Atekmangoh, C. (2017). "Les Mbengis" migration, gender, and family: The moral economy of transnational migrant Cameroonian remittances. Bamenda: Langaa.

Awasom, N. (2020). The Anglophone problem in Cameroon yesterday and today in search of a definition. Journal of the African Literature Association, 14(2), 264-291.

Carling, J. (2003). Aspiration and ability in international migration: Cape Verdean experiences of mobility and immobility. Oslo: University of Oslo.
Carling, J. (2013). Steps toward a theory of migration aspirations. Paper presented at the Aspirations and Capabilities in Migration Processes Conference, International Migration Institute, Oxford, UK.

Carling, J. (2014). The role of aspirations in migration. Paper presented at the Determinants of International Migration Conference, International Migration Institute, Oxford, UK.

Carling, J., \& Collins, F. (2018). Aspiration, desire and drivers of migration. Journal of Ethnic and Migration Studies, 44(6), 909-926.

Carling, J., \& Schewel, K. (2018). Revisiting aspiration and ability in international migration. Journal of Ethnic and Migration Studies, 44(6), 945-963.

Charmaz, K. (2006). Constructing grounded theory: $A$ practical guide through qualitative analysis. London: SAGE Publications.

Cohen, J., \& Sirkeci, I. (2011). Cultures of Migration: The global nature of contemporary mobility. Austin, TX: University of Texas Press.

Collier, P. (2013). Exodus: How migration is changing our world. Oxford: Oxford University Press.

Crivello, G. (2011). 'Becoming somebody': Youth transitions through education and migration in Peru. Journal of Youth Studies, 14(4), 395-411.

De Haas, H. (2011). The determinants of international migration: Conceptualising policy, origin and destination effects (IMI Working Paper No. 320). Oxford: IMI.

De Haas, H. (2014). Migration theory: Qua vadis (IMI Working Paper No. 100). Oxford: IMI.

Eggert, W., Krieger, T., \& Meier, V. (2010). Education, unemployment and migration. Journal of Public Economics, 94, 354-362.

Fassin, D. (2005). Compassion and repression: The moral economy of immigration policies in France. Cultural Anthropology, 20(3), 362-387.

Fokwang, J. (2008). Being young in old town: Youth subjectivities and associational life in Bamenda (Unpublished Doctoral dissertation). University of Toronto, Toronto, Canada.

Jua, N. (2003). Differential responses to disappearing transitional pathways: Redefining possibility among Cameroonian youths. African Studies Review, 46(2), 13-36.

Kandel, W., \& Massey, D. S. (2002). The culture of Mexican migration: A theoretical and empirical analysis. Social Forces, 80(3), 981-1004.

Konings, P. (2009). Neoliberal Bandwagonism: Civil society and the politics of belonging in Anglophone Cameroon. Bamenda and Leiden: Langaa/African Studies Centre.

Konings, P. (2011). Crisis and neoliberal reforms in Africa: Civil society and agro-industry in Anglophone Cameroon's plantation economy. Bamenda and Leiden: Langaa/African Studies Centre.

Konings, P., \& Nyamnjoh, F. (1997). The anglophone problem in Cameroon. The Journal of Modern African Studies, 35(2), 207-229. 
Nyamnjoh, F. (2011). Cameroonian bushfalling: Negotiation of identity and belonging in fiction and ethnography. American Ethnologist, 38(4), 701-713.

Nyamnjoh, H. (2014). Bridging mobilities: ICTs appropriation by Cameroonians in South Africa and the Netherlands. Bamenda: Langaa RPCIG/African Studies Centre.

Nyamnjoh, H. (2020). Entrepreneurialism and innovation among Cameroonian street vendors in Cape Town. African Identities, 18(3), 295-312.

Nyamnjoh, F., \& Page, B. (2002). Whiteman Kontri and the enduring allure of modernity among Cameroonian youth. African Affairs, 101, 607-634.

Ramos, R. (2019). Migration aspirations among youth in the Middle East and North Africa region. Journal of Geographical Systems, 21, 487-507.

Reader, A. (2009). Peace studies and conflict resolution in Nigeria. Ibadan: Spectrum Books.

Schewel, K., \& Fransen, S. (2018). Formal education and migration aspirations in Ethiopia. Population and Development Review, 44(3), 555-587.
Theo, S. (2003). Dreaming inside a walled city: Imagination, gender and the roots of immigration. Asian \& Pacific Migration Journal, 12(4), 411-438.

Timmerman, C., Hemmerechts, K., \& De Clerck, H. M.-L. (2014). The relevance of a "culture of migration" in understanding migration aspirations. Contemporary Turkey, Turkish Studies, 15(3), 496-518.

Ullah, A. (2013). Theoretical rhetoric about migration networks: A case of a journey of Bangladeshi workers to Malaysia. International Migration, 51(3), 151-168.

Van Mol, C. (2016). Migration aspirations of European youth in times of crisis. Journal of Youth Studies, 19(10), 1303-1320.

Van Mol, C., Snel, E., Hemmerechts, K., \& Timmerman, C. (2018). Migration aspirations and migration cultures: A case study of Ukrainian migration towards the European Union. Population, Space and Place, 24, 1-11.

Waters, J. (2006). Geographies of cultural capital: Education, international migration and family strategies between Hong Kong and Canada. Transactions of the Institute of British Geographers, 31, 179-192.

\section{About the Author}

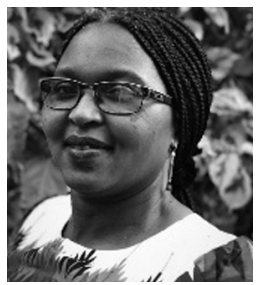

Henrietta Nyamnjoh (PhD) is a Researcher with the South-South Migration, Inequality and Development Hub at the University of Cape Town. Her research interests include migration and mobility, transnational studies, drawing attention to migrants' appropriation of information and communication technologies, migrant hometown associations, the migrant economy and everyday life and migration and health. Additionally, Henrietta is interested in understanding religion in the context of migration. She has researched and published widely on migration and Pentecostal religious healing among migrants in South Africa. 